Western University

Scholarship@Western

$1-3-2019$

\title{
Effects of prenatal exercise on fetal heart rate, umbilical and uterine blood flow: a systematic review and meta-analysis
}

\author{
Rachel J. Skow \\ University of Alberta \\ Margie H. Davenport \\ University of Alberta \\ Michelle Mottola \\ The University of Western Ontario \\ Gregory A. Davies \\ Queen's University \\ Veronica j. Poitras
}

See next page for additional authors

Follow this and additional works at: https://ir.lib.uwo.ca/anatomypub

Part of the Anatomy Commons, and the Cell and Developmental Biology Commons

\section{Citation of this paper:}

Skow, Rachel J.; Davenport, Margie H.; Mottola, Michelle; Davies, Gregory A.; Poitras, Veronica j.; Gray, Casey E.; Garcia, Alejandra Jaramillo; Barrowman, Nick; Meah, Victoria L.; Slater, Linda G.; Adamo, Kristi B.; Barakat, Ruben; and Ruchat, Stephanie-May, "Effects of prenatal exercise on fetal heart rate, umbilical and uterine blood flow: a systematic review and meta-analysis" (2019). Anatomy and Cell Biology

Publications. 319.

https://ir.lib.uwo.ca/anatomypub/319 


\section{Authors}

Rachel J. Skow, Margie H. Davenport, Michelle Mottola, Gregory A. Davies, Veronica j. Poitras, Casey E. Gray, Alejandra Jaramillo Garcia, Nick Barrowman, Victoria L. Meah, Linda G. Slater, Kristi B. Adamo, Ruben Barakat, and Stephanie-May Ruchat 


\title{
Effects of prenatal exercise on fetal heart rate, umbilical and uterine blood flow: a systematic review and meta-analysis
}

\author{
Rachel J Skow, ${ }^{1}$ Margie H Davenport, ${ }^{1}$ Michelle F Mottola, ${ }^{2}$ Gregory A Davies, ${ }^{3}$ \\ Veronica J Poitras, ${ }^{4}$ Casey E Gray, ${ }^{5}$ Alejandra Jaramillo Garcia, ${ }^{4}$ Nick Barrowman, ${ }^{6}$ \\ Victoria L Meah, ${ }^{1}$ Linda G Slater, ${ }^{7}$ Kristi B Adamo, ${ }^{8}$ Ruben Barakat, ${ }^{9}$ \\ Stephanie-May Ruchat ${ }^{10}$
}

- Additional material is published online only. To view please visit the journal online (http://dx.doi.org/10.1136/ bjsports-2018-099822).

For numbered affiliations see end of article.

\section{Correspondence to} Dr Margie H Davenport, Program for Pregnancy and Postpartum Health, Faculty of Kinesiology, Sport, and Recreation, University of Alberta, Edmonton, AB T6G 2R3, Canada

mdavenpo@ualberta.ca

Accepted 11 August 2018 Published Online First 18 October 2018
Check for updates

(C) Author(s) (or their employer(s)) 2019. No commercial re-use. See rights and permissions. Published by BMJ.

To cite: Skow RJ,

Davenport MH, Mottola MF, et al. Br J Sports Med

2019:53:124-133.

\section{ABSTRACT}

Objective To perform a systematic review and metaanalysis examining the influence of acute and chronic prenatal exercise on fetal heart rate (FHR) and umbilical and uterine blood flow metrics.

Design Systematic review with random-effects metaanalysis and meta-regression.

Data sources Online databases were searched up to 6 January 2017

Study eligibility criteria Studies of all designs were included (except case studies) if published in English, Spanish or French, and contained information on the population (pregnant women without contraindication to exercise), intervention (subjective or objective measures of frequency, intensity, duration, volume or type of exercise, alone ["exercise-only"] or in combination with other intervention components [eg, dietary; "exercise + co-intervention"]), comparator (no exercise or different frequency, intensity, duration, volume and type of exercise) and outcomes (FHR, beats per minute (bpm); uterine and umbilical blood flow metrics (systolic:diastolic (S/D) ratio; Pulsatility Index (PI); Resistance Index (RI); blood flow, mL/min; and blood velocity, $\mathrm{cm} / \mathrm{s})$ ).

Results 'Very low' to 'moderate' quality evidence from 91 unique studies ( $n=4641$ women) were included. Overall, FHR increased during (mean difference $(\mathrm{MD})=6.35 \mathrm{bpm} ; 95 \% \mathrm{Cl} 2.30$ to $10.41, \mathrm{I}^{2}=95 \%$, $\mathrm{p}=0.002)$ and following acute exercise (MD=4.05; $95 \% \mathrm{Cl} 2.98$ to $\left.5.12, \mathrm{I}^{2}=83 \%, \mathrm{p}<0.00001\right)$. The incidence of fetal bradycardia was low at rest and unchanged with acute exercise. There were no significant changes in umbilical or uterine $S / D, P I, R I$, blood flow or blood velocity during or following acute exercise sessions. Chronic exercise decreased resting FHR and the umbilical artery S/D, PI and RI at rest.

Conclusion Acute and chronic prenatal exercise do not adversely impact FHR or uteroplacental blood flow metrics.

\section{INTRODUCTION}

The impact of prenatal exercise on blood flow to the uterus, placenta and ultimately the fetus has long been debated. Early research suggested prenatal exercise may increase the risk of fetal bradycardia $(<110 \mathrm{bpm}),^{1-3}$ and that this was potentially in response to maternal cardiac output being redistributed away from the fetus towards the working

\section{What is already known}

- Fetal heart rate is hypothesised to increase during exercise due to decreases in blood flow to the fetus (uterine or umbilical blood flow).

- The incidence of bradycardia (fetal heart rate $<110 \mathrm{bpm}$; indication of fetal distress) has been found to increase during exercise.

\section{What are the new findings}

Fetal heart rate was increased during exercise by an average of $6 \mathrm{bpm}$ and following exercise by $4 \mathrm{bpm}$. The increase was greater in the third trimester of pregnancy and with activities greater than 20 minutes in duration.

- The magnitude of increase in fetal heart rate following exercise may be affected by the method of measurement (2D ultrasound vs Doppler ultrasound vs electronic fetal monitor).

- The incidence of bradycardia during and following acute exercise was not elevated compared with rest.

- Uterine and umbilical blood flow were not changed during or following acute exercise.

muscle. ${ }^{4}$ In non-pregnant rabbits, uterine blood flow decreased during exercise, but this change was attenuated in pregnant animals. ${ }^{5}$ In humans, umbilical and uterine systolic/diastolic ratio is used to determine whether there are abnormalities to fetal circulation and reflect the resistance at the placenta. ${ }^{6}$ If resistance is increased, oxygen transfer at the placenta is less effective and fetal hypoxia (and therefore intrauterine growth restriction) is more likely. ${ }^{6}$

Whether exercise alters umbilical or uterine blood flow metrics (systolic: diastolic ratio, Pulsatility Index and Resistance Index) in humans has not been evaluated systematically. A 2016 narrative review concluded that maternal exercise is well tolerated by the fetus, ${ }^{7}$ and a recent meta-analysis reported that maternal exercise does not restrict fetal growth. ${ }^{8}$ However, to date, a quantitative analysis of fetal heart rate (FHR), umbilical and uterine blood flow responses to maternal exercise 
has not been conducted comparing exercise intensity, duration, volume or type to determine if there are specific exercises that may result in an abnormal FHR response.

Current international and national guidelines for prenatal exercise encourage all women without contraindication to be physically active during pregnancy. ${ }^{9-11}$ The present meta-analysis was conducted as part of a series of reviews, which will form the evidence base for the development of the 2019 Canadian guideline for physical activity throughout pregnancy (herein referred to as Guideline). ${ }^{12}$ The aim of this systematic review and meta-analysis is to summarise the effects of acute and chronic prenatal exercise on FHR, and umbilical and uterine blood flow metrics (ie, absolute volumetric blood flow, blood velocity, systolic:diastolic ratio, Pulsatility Index and Resistance Index).

\section{METHODS}

The Guidelines Consensus Panel assembled in October 2015 to identify priority outcomes for the Guideline update. This panel included researchers, methodological experts, a fitness professional and representatives from the Canadian Society for Exercise Physiology (CSEP), the Society of Obstetricians and Gynaecologists of Canada (SOGC), the College of Family Physicians of Canada, the Canadian Association of Midwives, the Canadian Academy of Sport and Exercise Medicine, Exercise is Medicine Canada and a representative health unit (the Middlesex-London Health Unit). Twenty 'critical' and 17 'important' outcomes related to prenatal exercise and maternal/fetal health were selected by the Guidelines Consensus Panel. FHR, and umbilical and uterine blood flow were rated as 'critical' and are examined in this review. This systematic review and meta-analysis was conducted in accordance with the Preferred Reporting Items for Systematic Reviews and Meta-Analyses (PRISMA) guidelines including the completion of the checklist. ${ }^{13}$

\section{Protocol and registration}

Initially, the impact of prenatal exercise on each fetal and maternal health outcome was registered with PROSPERO, the international prospective register of systematic reviews as two separate systematic reviews (fetal health registration no. CRD42016029869; maternal health registration no. CRD42016032376). However, as the relationships between prenatal exercise and these outcomes were examined in studies related to both fetal and maternal health, records retrieved from the searches from both of these reviews were evaluated for inclusion in the present study.

\section{Eligibility criteria}

The eligibility criteria for this meta-analysis was guided by the PICOS framework: participants, interventions, comparisons, outcomes and study design. ${ }^{14}$

\section{Population}

The population of interest was pregnant women without absolute or relative contraindication to exercise as defined by the 2003 SOGC/CSEP Clinical Practice Guidelines for Exercise During Pregnancy. ${ }^{9}{ }^{15}$ Absolute contraindications to exercise were defined as (1) ruptured membranes, (2) premature labour, (3) persistent second or third trimester bleeding, (4) placenta previa, (5) pre-eclampsia, (6) gestational hypertension, (7) incompetent cervix, (8) intrauterine growth restriction, (9) highorder pregnancy, (10) uncontrolled type 1 diabetes, (11) hypertension or thyroid disease, or (12) other serious cardiovascular, respiratory or systemic disorders. ${ }^{915}$ Relative contraindications to exercise were defined as (1) a history of spontaneous abortion, (2) premature labour, (3) mild/moderate cardiovascular or respiratory disease, (4) anaemia or iron deficiency, (5) malnutrition or eating disorder, (6) twin pregnancy after 28 weeks or (7) other significant medical conditions. ${ }^{915}$

\section{Intervention (exposure)}

Studies were eligible if they reported any objective or subjective measures of exercise including the following: (1) frequency, (2) intensity, (3) duration, (4) volume or (5) type of exercise. Although exercise is a subtype of physical activity, for the purpose of this review we used the terms interchangeably and defined them as any bodily movement generated by skeletal muscles that resulted in energy expenditure above resting levels. ${ }^{16}$ Acute (ie, a single exercise session) or chronic (ie, usual or habitual activity) prenatal exercise as well as interventions including exercise alone (termed 'exercise-only' interventions) or in combination with other interventions (eg, diet; termed 'exercise+co-interventions') were considered. Studies were not eligible if exercise was performed after the beginning of labour.

\section{Comparison}

Eligible comparators were: no exercise, or a different frequency, intensity, duration, volume or type of exercise, or exercise in a different trimester.

\section{Outcome}

Relevant outcomes were FHR (including incidence of bradycardia $(<110 \mathrm{bpm})$ and tachycardia $(>160 \mathrm{bpm}))$, uterine and umbilical artery blood flow metrics (measured as absolute blood flow $(\mathrm{mL} / \mathrm{min})$, mean velocity $(\mathrm{cm} / \mathrm{s})$, systolic:diastolic ratio, Pulsatility Index and Resistance Index).

\section{Study design}

All study designs were eligible except for case studies $(n=1)$ and non-original research (eg, review) with the following caveat. For studies examining the impact of acute maternal exercise on outcomes, all study designs were included. For studies examining the impact of chronic maternal exercise on resting values, a staged approach was used to determine if there was sufficient evidence from randomised controlled trials (RCTs) for each outcome to inform the Guideline or if it was necessary to consider other study designs. If fewer than 2000 women were included in the meta-analysis, the impact of chronic prenatal exercise on the specific outcome was examined further using observational evidence (non-randomised interventions, cohort, cross-sectional and case-control studies).

\section{Information sources}

A comprehensive search was created and run by a research librarian (LGS) in the following databases: MEDLINE, EMBASE, PsycINFO, Cochrane Database of Systematic Reviews, Cochrane Central Register of Controlled Trials, Scopus and Web of Science Core Collection, CINAHL Plus with Full-text, Child Development and Adolescent Studies, ERIC, Sport Discus, ClinicalTrials. gov and the Trip Database up to 6 January 2017 (see online supplement for complete search strategies).

\section{Study selection and data extraction}

Two separate reviewers independently screened the titles and abstracts of all retrieved articles for inclusion or exclusion. Articles that were selected for inclusion by at least one reviewer were acquired as full-text articles. All included articles from either 
fetal health or maternal health search strategies were imported into DistillerSR (Evidence Partners, Ottawa, Ontario, Canada) and from this point forward were considered as one review. All full-text articles were independently screened by two reviewers for inclusion criteria prior to extraction. All articles that were recommended for exclusion were further reviewed by MHD before a final decision on exclusion was made. In the event of a disagreement, the study characteristics were presented to the Guidelines Steering Committee (MHD, MFM, S-MR, CEG, VJP, AJG and NB) who oversaw the systematic reviews for a final decision regarding inclusion/exclusion by consensus. Selected studies were imported into DistillerSR (Evidence Partners) for data extraction. At this point, duplicate studies from the maternal and fetal reviews were removed in DistillerSR and all included studies were considered as part of one review.

Data extraction was completed using DistillerSR in consultation with methodological experts and the Guidelines Steering Committee. Data were extracted independently by one person and verified by a content expert (MHD, MFM or S-MR). The following data were extracted from each publication: (1) study characteristics (ie, year, study design, country), (2) characteristics of the population (eg, number of participants, age, pre-pregnancy Body Mass Index (BMI), parity and pregnancy complications), (3) intervention/exposure (frequency, intensity, duration, volume and type of exercise, duration of intervention and/or measure of physical activity) and (4) relevant outcomes (FHR, umbilical and uterine blood flow metrics).

\section{Quality of evidence assessment}

The quality of evidence was assessed using the Grading of Recommendation Assessment, Development and Evaluation (GRADE) framework for each study design and outcome. RCTs began with a 'high' quality of evidence assessment and were graded down if any of the following issues occurred: (1) risk of bias, (2) indirectness, (3) inconsistency, (4) imprecision, (5) risk of publication bias and (6) other risk of bias. All non-randomised interventions and observational studies began with a 'low' quality assessment and, if there was no cause to downgrade, were upgraded if applicable according to the GRADE criteria (eg, large magnitude of effect, evidence of dose response). ${ }^{17}$ For acute exercise data, we combined all study types (RCT, non-randomised interventions, cross-sectional, cohort and case report) and treated them as observational studies for GRADE assessment.

Specifically, the risk of bias in RCTs and intervention studies was assessed following the Cochrane Handbook ${ }^{18}$ and the risk of bias in observational studies was assessed using the characteristics recommended by Guyatt $e t a l,{ }^{19}$ which has been used by other Physical Activity systematic reviews. All studies (RCTs, intervention studies and observational studies) were evaluated for potential sources of bias including selection bias (RCT/intervention: inadequate randomisation procedure; observational: inappropriate sampling), reporting bias (selective/incomplete outcome reporting), performance bias (RCT/intervention: compliance to the intervention; observational: flawed measurement of exposure), detection bias (flawed measurement of outcome), attrition bias (incomplete follow-up, high loss to follow-up) and 'other' sources of bias. Risk of bias across studies was rated as 'serious' when studies having the greatest influence on the pooled result (assessed using weight (\%) given in forest plots or sample size in studies that were narratively synthesised) presented 'high' risk of bias. The greatest influence on the pooled result was determined as follows: the studies that had the greatest individual per cent contribution in the meta-analyses, when taken together, contributed to $>50 \%$ of the weight of the pooled estimate. Serious risk of bias was considered when the sample size of studies that were narratively synthesised was similar to the total sample size of studies contributing to $>50 \%$ of the weight of the pooled estimate in the meta-analyses. Given the nature of exercise interventions, it is not possible to blind participants to group allocation. Therefore, if the only source of bias was related to the blinding of allocation, the risk of bias was rated as 'low'. Performance bias was rated as 'high' when $<60 \%$ of participants performed $100 \%$ of prescribed exercise sessions or attended $100 \%$ of counselling sessions (defined as low compliance) or when compliance to the intervention was not reported. Attrition bias was rated as 'high' when $>10 \%$ of data were missing at the end of the study and intention-to-treat analysis was not used.

Indirectness was considered serious when a co-intervention (eg, diet) and was included in the analysis of the effect of exercise on the outcome of interest. Inconsistency was considered serious when heterogeneity was high $\left(\mathrm{I}^{2} \geq 50 \%\right)$ or when only one study was assessed ( $\mathrm{I}^{2}$ unavailable). Imprecision was considered serious when the $95 \%$ CI crossed the line of no effect, and was wide, such that interpretation of the data would be different if the true effect were at one end of the CI or the other. When only one study was assessed, imprecision was not considered serious because inconsistency was already considered serious for this reason. Finally, in order to assess publication bias, funnel plots were created if at least 10 studies were included in the forest plot (see online supplement figures 71 and 72). If there were fewer than 10 studies, publication bias was deemed non-estimable and not rated down. Due to time constraints and feasibility, one reviewer evaluated the quality of the evidence across each health outcome using the protocol and a second person reviewed the GRADE tables as a quality control measure. Quality of evidence assessment is presented in online supplement tables 3-10.

\section{Statistical analysis}

Review Manager V.5.3. (Cochrane Collaboration, Copenhagen, Denmark) was used to conduct the statistical analyses and create the forest plots and funnel plots. Statistical significance was set at $\mathrm{p}$ value $<0.05$. For the acute exercise data, change scores were calculated using the generic inverse variance method (Cochrane Collaboration).$^{18}$ FHR response during exercise was defined as the mean difference between baseline FHR and FHR during exercise. Post-exercise FHR response was defined as the mean difference between baseline and post-exercise (first given measure up to 20 minutes following exercise) FHR values. The $\mathrm{SD}$ of the change score was determined assuming a correlation of 0.5 and then converted into SE. All instances of acute exercise that reported the outcome of interest were combined onto a single forest plot regardless of study type (ie, single exercise sessions from RCTs were combined with single exercise sessions from cross-sectional studies where women only exercised once).

Where possible, if SD were not reported, they were estimated using the $\mathrm{p}$ values according the Cochrane handbook procedures outlined in section 7.3.3.3. ${ }^{18}$ Similarly, when data were reported as medians and IQRs, values were converted to means and SD according to section 7.3.3.5 of the Cochrane handbook. ${ }^{18}$ For data from acute exercise sessions, the changes from baseline (rest) to exercise or recovery were calculated (mean difference). The SD of the change scores were calculated according to the Cochrane handbook section 7.7.3.3. ${ }^{18}$ From the calculated $\mathrm{SD}$, we estimated SE based on the number of participants in the studies. When repeated measures (eg, multiple time points) were reported for each participant, the sample size was divided 
by the number of time points to avoid exaggerating the sample size through double (or triple etc) counting. Furthermore, if the number of participants varied at each time point, then a weighted $\mathrm{n}$ was used to determine the SE. If data were unavailable for extraction (ie, not reported or only presented in figures), the authors were contacted to request additional information. If authors did not provide the information, data from figures were extracted by digitising graphs using GetData Graph Digitizer (V.2.26). ${ }^{20}$

A priori-determined subgroup analyses were conducted. Tests for subgroup analyses were conducted, and significance was set at $\mathrm{p}$ value $<0.05$. When statistically significant differences were found, subgroup differences were interpreted. These subgroups included (1) women diagnosed with diabetes (gestational, type 1 or type 2) compared with women without specific pregnancy complications, (2) women with overweight or obesity status (mean BMI $>25.0 \mathrm{~kg} / \mathrm{m}^{2}$ ) compared with samples of women who were of various BMI (mean BMI $<25 \mathrm{~kg} / \mathrm{m}^{2}$, which may include some individuals with BMI $>25.0 \mathrm{~kg} / \mathrm{m}^{2}$ ), (3) women $\geq 35$ years of age compared with women $<35$ years of age, (4) women who were previously active compared with women who were previously inactive (author defined) and (5) different types of exercise compared with one another (eg, aerobic, resistance training, yoga, various (mixed) type of exercise). If a study did not provide sufficient detail to allow it to be grouped into the a priori subgroups, then a third group called 'unspecified' was created.

The per cent of total variability that is attributable to betweenstudy heterogeneity (ie, not to chance) was expressed using the I-squared $\left(\mathrm{I}^{2}\right)$ statistic. We performed additional post hoc subgroup analysis using the random-effects model on the following criteria when the a priori subgroups did not explain the heterogeneity in response (ie, $\mathrm{I}^{2}>50 \%$ within the a priori subgroups): (1) trimester in which exercise was performed; (2) intensity in which exercise was performed; (3) duration of exercise session; (4) method of determining FHR (for FHR measures only; eg, electronic fetal monitor, 2D ultrasound, Doppler ultrasound). For exercise intensity classification, we used the scale outlined by Norton $e t a l^{21}$ and combined sedentary/low and vigorous/high to give three distinct categories of exercise intensity (ie, low, moderate and vigorous). Where more than one objective measurement was given, maternal heart rate was used to classify intensity of the exercise. When objective measures were not used to determine exercise intensity, the prescribed intensity was assumed. For duration, a priori groupings were defined as $0-20 \mathrm{~min}, 21-40 \mathrm{~min}$ and $40+\mathrm{min}$. If the duration was reported as a range, the midpoint was used. If a study did not provide sufficient detail to allow for inclusion into the a priori subgroups, then a third group called 'unspecified' was created.

Further, meta-regression was conducted to examine the relationship between the exercise volume (MET-minutes; METs for activity $\times$ duration of activity) and the outcome variable (eg, FHR). If the duration or the intensity could not be determined from the paper (ie, volume could not be determined), the study was not included in the meta-regression. Dose-response meta-regression was carried out by weighted no-intercept regression of $\log$ OR with a random-effects model for study, using the metaphor package in R V.3.4.1. Models did not include an intercept term since the log OR was assumed to be zero when the exercise dose is zero. Restricted cubic splines with knots at the 10th, 50th and 90th percentiles of the explanatory variable were used to investigate whether there was evidence for a non-linear relationship. Fitting was by maximum likelihood, and non-linearity was assessed using a likelihood ratio test. Linear models were presented unless the fit of the spline was significantly better $(p<0.05)$. The results from this analysis are given in the online supplement (Meta-regressions).

To assess the incidence of bradycardia or tachycardia during or following exercise (up to $20 \mathrm{~min}$ ), we assessed all the manuscripts that explicitly reported bradycardia or tachycardia (as defined by the study authors), including those which specifically said that no incidence of bradycardia/tachycardia occurred. We included studies where raw data for each participant were given. For the latter, we used a definition of bradycardia as $<110 \mathrm{bpm}$ and tachycardia as being FHR $>160 \mathrm{bpm}$ based on the 2008 guidelines from the National Institute of Child Health and Human Development. ${ }^{3}$ Bradycardia and tachycardia incidence (proportion) were determined in RStudio using a custom program written by NB. The results from this analysis are included in the online supplement (Proportions).

Within each outcome, results are organised first by acute exercise responses (all study designs combined) and then by chronic exercise responses (presented based on study design). For outcomes where a meta-analysis was not possible, results were presented as a narrative synthesis, structured around each outcome.

\section{RESULTS}

\section{Study selection}

The initial search was not limited by language. However, the Guidelines Steering Committee decided to exclude studies published in languages other than English, Spanish or French for feasibility reasons. A PRISMA diagram of the search results, including reasons for exclusion, is shown in figure 1. A comprehensive list of excluded studies is presented in the online supplement.

\section{Study characteristics}

Overall, 91 unique studies from 92 manuscripts $(n=4641$ women) from 19 countries (six continents) were included. There were 12 RCTs, 6 non-randomised interventions, 43 cohort, 27 cross-sectional and 3 case-control studies. Among the included chronic exercise-only interventions (there were no co-interventions reported in any paper), the frequency ranged from 2 to 7 days per week, at low and moderate intensities ranging from 15 to $60 \mathrm{~min}$ per session. Exercise interventions took place starting in the second and third trimesters, ranging from 7 to 25 weeks in duration, and the types of exercise included walking, cycling, water aerobics, swimming, yoga, pelvic floor muscle training and a combination of various types of exercise. Among the included acute exercise sessions, there were low, moderate and vigorous to high-intensity activities, ranging from 3 to $60 \mathrm{~min}$ per session. Exercise sessions took place in the second and third trimester, and the types of exercise included walking, swimming, cycling, water aerobics, resistance training and yoga. Additional details regarding the studies can be found in the online supplement (Study characteristics and tables 1 and 2).

\section{Quality of evidence}

Overall, the quality of evidence for the effects of prenatal exercise on changes in FHR, umbilical or uterine blood flow measured both during or following acute exercise was rated as 'very low' or 'low' (see online supplement tables 3, 4, 6,7 and 9). The most common reasons for downgrading the quality of evidence were serious inconsistency due to high heterogeneity $\left(\mathrm{I}^{2}>50 \%\right)$ or where heterogeneity was not estimable (one study). The quality of evidence for the effects of chronic exercise on changes in 
Maternal

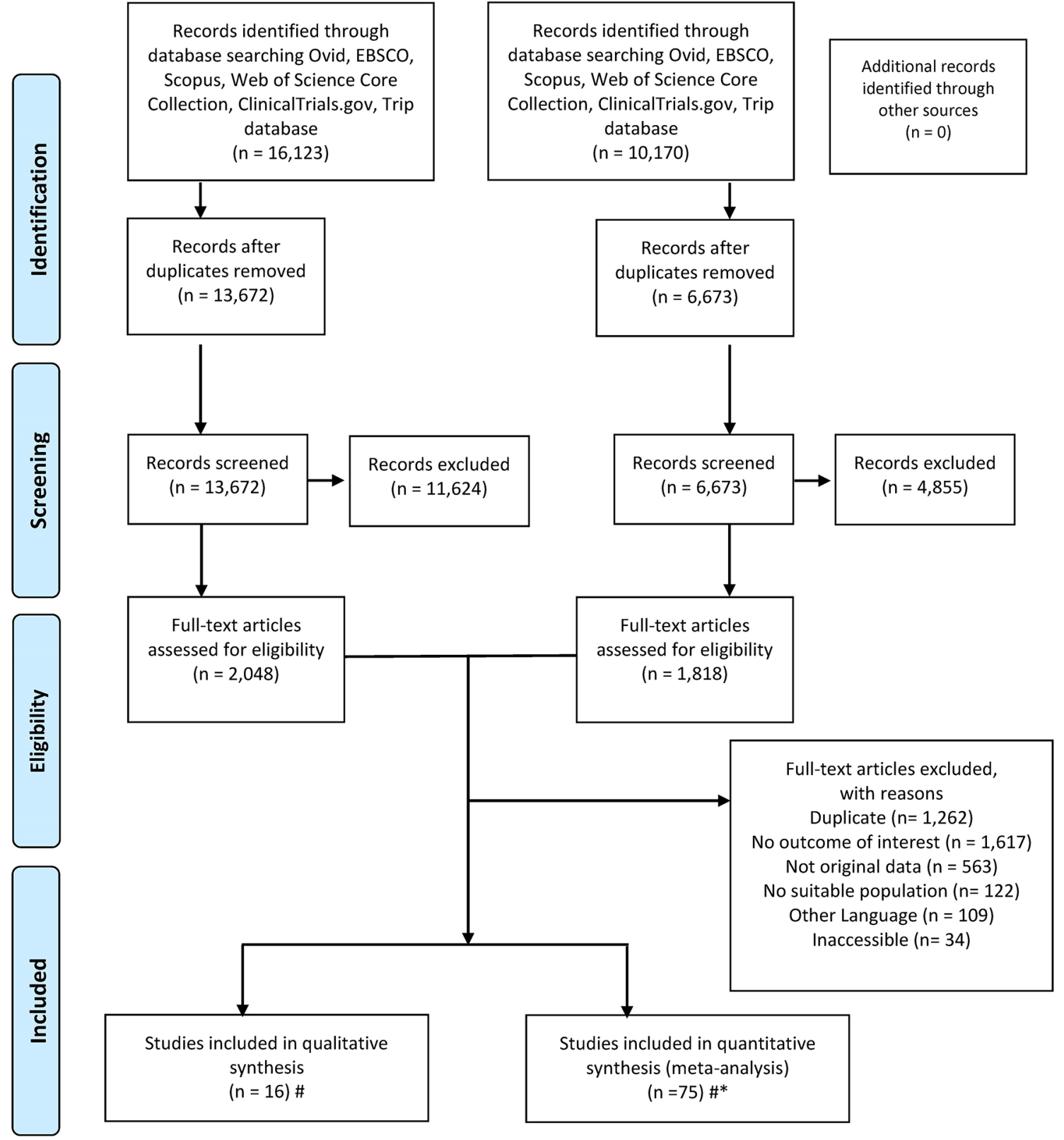

Figure 1 Preferred Reporting Items for Systematic Reviews and Meta-Analyses flow diagram of selected studies. "Five studies were included in both the qualitative and quantitative synthesis. *76 manuscripts were included in the quantitative synthesis, but 2 manuscripts reported on the same study; therefore, 75 unique studies were included.

resting FHR and the FHR response to acute exercise was rated as 'very low' to 'moderate' (see online supplement tables 5, 8 and 10). The most common reasons for downgrading the quality of evidence were serious risk of bias, inconsistency $\left(\mathrm{I}^{2}>50 \%\right)$ and imprecision (wide CI). Common sources of bias included attrition bias and performance bias. No evidence of publication bias was observed.

\section{Synthesis of data}

\section{Fetal heart rate}

No studies reported on FHR in the first trimester of pregnancy. Resting FHR ranged from 138.0 to $157.4 \mathrm{bpm}$ in the second trimester across 20 studies ( $\mathrm{n}=581$ women). ${ }^{22-41}$ Resting FHR ranged from 125.0 to $151.0 \mathrm{bpm}$ in the third trimester across 50 studies ( $\mathrm{n}=1581$ women). $122252729-3335-38$ 40-75

Fetal heart rate response during acute exercise

Overall, there was 'very low' quality evidence from 19 studies $(n=348$ women) examining FHR before and during acute maternal exercise. ${ }^{1222325-2742-47566875-79}$ The quality of evidence was downgraded from 'low' to 'very low' due to serious inconsistency. Fifteen studies were included in the pooled analysis $(n=291$ women) and showed a mean increase in FHR of 6.35 bpm during acute exercise (95\% CI 2.30 to $10.41, \mathrm{I}^{2}=95 \%$, $\mathrm{p}=0.002$, figure 2). ${ }^{122} 23252642-4756687577$ A post hoc sensitivity analysis was performed removing one trial ( $\mathrm{n}=6$ women) demonstrating a decrease in FHR of 58 bpm during exercise ${ }^{1}$; 


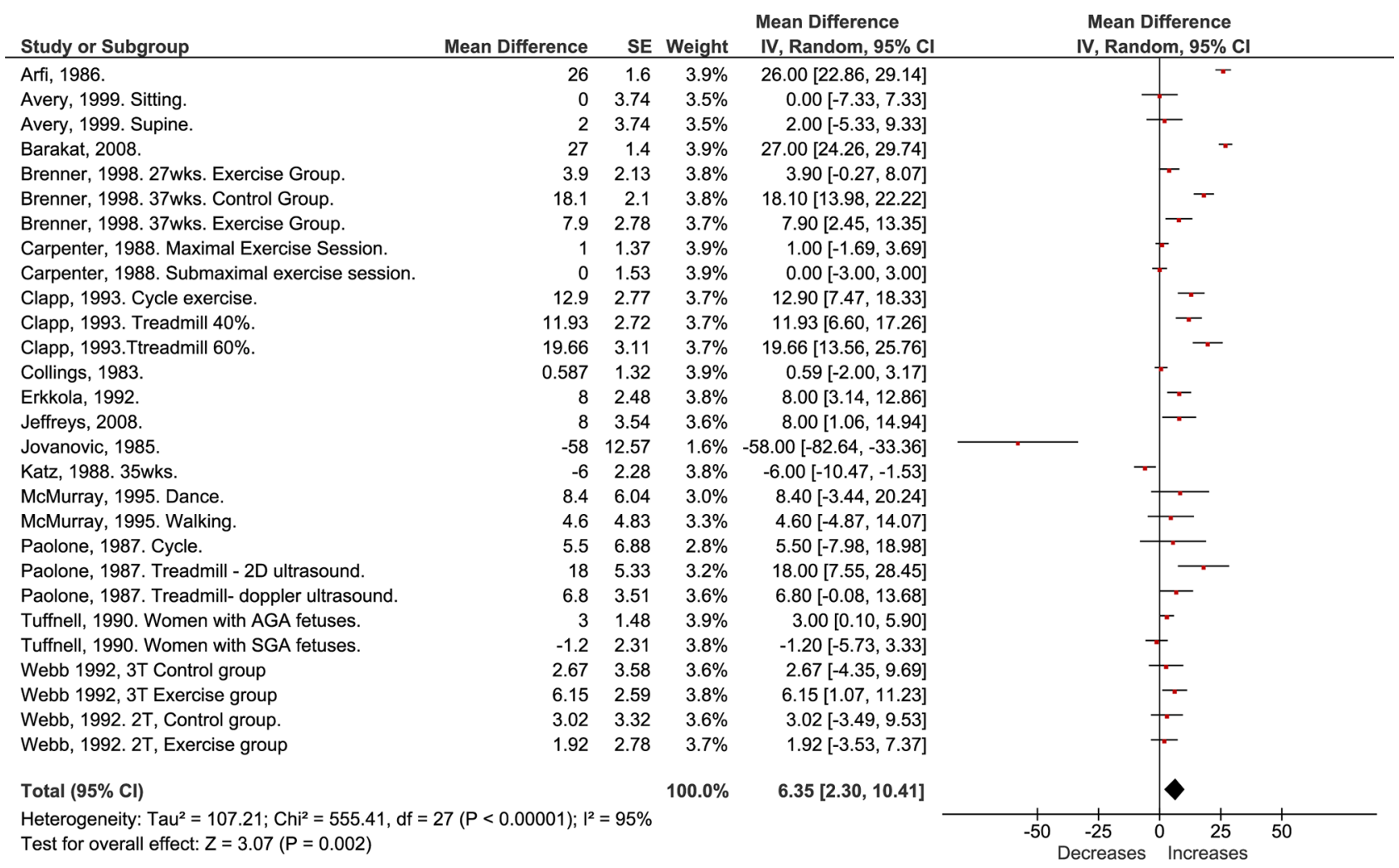

Figure 2 Effect of acute prenatal exercise on fetal heart rate during maternal exercise. Data reported as a mean difference compared with baseline (maternal rest). Analysis conducted using a random-effects model. 2T, second trimester; 3T, third trimester; AGA, average for gestational age; IV, inverse variance; SGA, small for gestational age.

the impact of prenatal exercise on FHR was similar (mean difference $(\mathrm{MD})=7.41 \mathrm{bpm}$; see online supplement figure 1$)$. Four studies could not be included in the pooled analysis due to missing SD, ${ }^{27} 78$ missing baseline values ${ }^{79}$ and insufficient figure quality $^{76}(\mathrm{n}=57$ women; see online supplement tables 1 and 2 for additional details). Two of these studies demonstrated that in response to a single bout of swimming exercise, FHR was increased by a mean of $2.0 \mathrm{bpm}^{27}$ and $7.0 \mathrm{bpm} .{ }^{78}$ One study demonstrated an increase in FHR by $6 \mathrm{bpm}$ in the second trimester and $9 \mathrm{bpm}$ in the third trimester during $5 \mathrm{~min}$ of resistance training exercises. ${ }^{79}$ We were unable to extract data from a fourth study due to insufficient figure quality; however, the authors reported that FHR did not differ between trimesters at rest and during exercise. ${ }^{76}$

In meta-regression analysis, we identified a curvilinear dose-response relationship between volume of exercise (MET minutes per session) and FHR during exercise $(\mathrm{p}<0.001$; see online supplement figure 75) indicating that mean FHR increased to a peak of $9.8 \mathrm{bpm}$ above resting baseline at 138.3 MET minutes, after which it plateaued or increased to a lesser extent.

\section{Subgroup analyses}

Tests for subgroup differences were not statistically significant (see online supplement figures 2-7).

Fetal heart rate response following acute exercise Overall, there was 'very low' quality evidence from 65 studies $(\mathrm{n}=1854$ women) examining the change in FHR from maternal rest to following acute maternal exercise (from 1 to $20 \mathrm{~min}$ ). The quality of evidence was downgraded from 'low' to 'very low' due to serious inconsistency. Fifty-four studies were included in the pooled analysis ( $\mathrm{n}=1494$ women) and showed a mean increase in FHR of $4.05 \mathrm{bpm}$ during acute exercise $(95 \% \mathrm{CI}$ $2.98,5.12, \mathrm{I}^{2}=83 \%, \mathrm{p}<0.00001$; see figure 3 ). Eleven studies ( $\mathrm{n}=360$ women) could not be included in the pooled analysis due to missing SD, 27788081 FHR reported as a range, ${ }^{82-84}$ missing values, ${ }^{85}$ unusable metrics (ie, percentage of maximal pulse $)^{79}$ or data were presented in figures that were not of high enough quality to be extracted digitally ${ }^{76}$ (see online supplement tables 1 and 2 for additional details). These studies reported an increase (mean increase ranged from 2 to $25 \mathrm{bpm})^{22778-83}$ or no change $\mathrm{e}^{76485}$ in FHR following exercise.

In the meta-regression analysis, we identified a curvilinear dose-response relationship between volume of exercise (MET minutes per session) and change in FHR from before to following exercise $(\mathrm{p}<0.01$; see online supplement figure 76 ). FHR following an acute exercise session increased to a peak of $7.2 \mathrm{bpm}$ above resting baseline at 174.6 MET minutes, after which it plateaued or increased to a lesser extent. However, all values were within the normal range.

\section{Subgroup analyses}

The tests for subgroup differences were only statistically significant when comparing studies including women engaging in different types of exercise (ie, aerobic activities (48 studies, $\mathrm{n}=1388$ women), resistance training activities ( 3 studies, $\mathrm{n}=46$ women) or yoga ( 2 studies, $\mathrm{n}=48$ women)) (a priori subgroup analysis, see online supplement figures 8-10). Specifically, there was 'very low' quality evidence (downgraded from 'low' to 'very low' due to serious inconsistency) showing that aerobic exercise resulted in a mean increase in FHR of $4.41 \mathrm{bpm}$ (95\% CI 


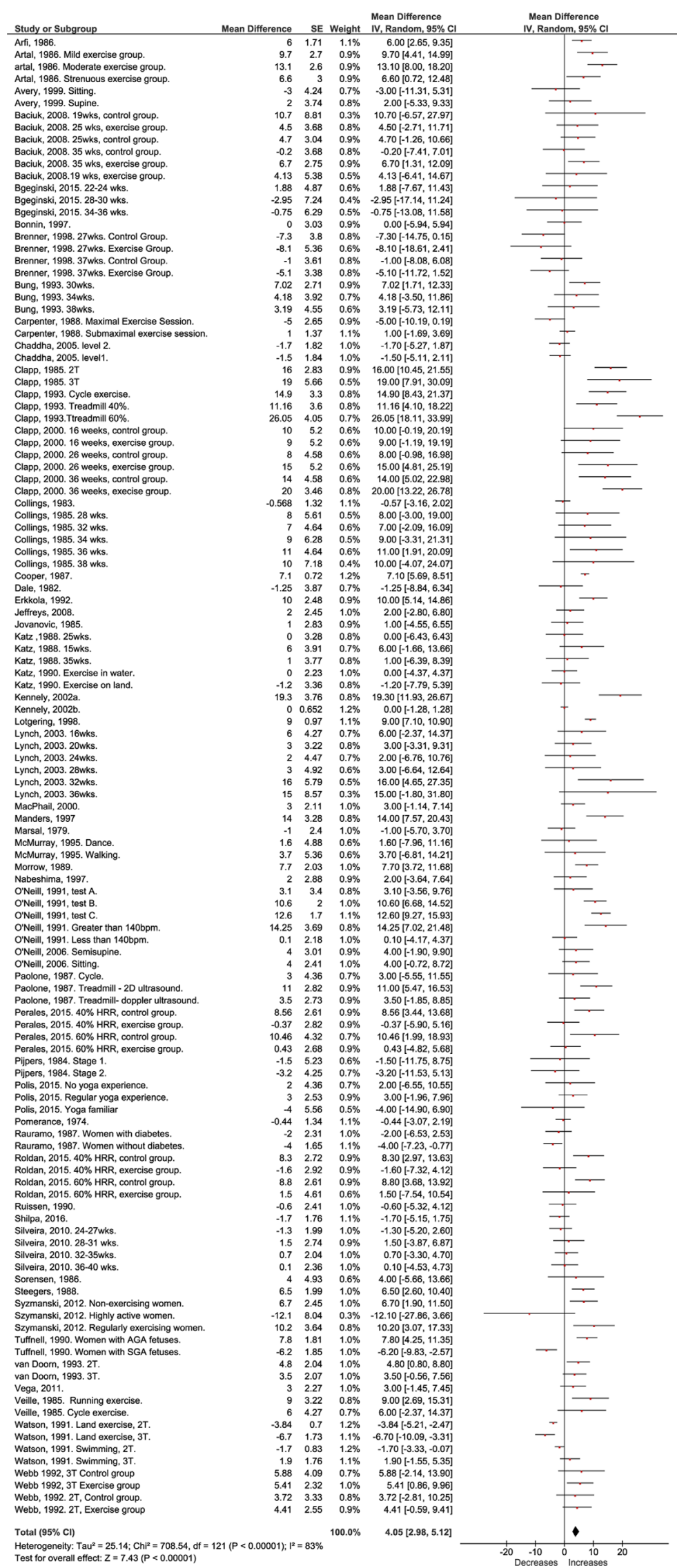

Figure 3 Effect of acute prenatal exercise on fetal heart rate (FHR) following maternal exercise. Data reported as a mean difference compared with baseline (maternal rest) conditions. Analysis conducted using a random-effects model. 2T, second trimester; 3T, third trimester; AGA, average for gestational age; HRR, heart rate reserve; IV, inverse variance; SGA, small for gestational age. 
3.28 to $\left.5.54, \mathrm{I}^{2}=84 \%, \mathrm{p}<0.00001\right)$, whereas resistance training sessions and yoga sessions resulted in no significant change in FHR $\left(\mathrm{MD}=0.38 \mathrm{bpm}, 95 \% \mathrm{CI}-2.26\right.$ to $3.02, \mathrm{I}^{2}=2 \%, \mathrm{p}=0.78$; $\mathrm{MD}=-0.17 \mathrm{bpm}, 95 \% \mathrm{CI}-2.82$ to $2.49, \mathrm{I}^{2}=0 \%, \mathrm{p}=0.90$, respectively; see online supplement figure 10).

The tests for subgroup differences were also statistically significant for some post hoc subgroup analyses (see online supplement figures 11-13). Specifically, there was 'very low' quality evidence (downgraded from 'low' to 'very low' due to serious inconsistency) reporting a mean increase in FHR of $2.01 \mathrm{bpm}$ (95\% CI 0.21 to $\left.3.80, \mathrm{I}^{2}=74 \%, \mathrm{p}=0.03\right)$ and $4.61 \mathrm{bpm}(95 \% \mathrm{CI}$ 3.36 to 5.86 . $\left.\mathrm{I}^{2}=81 \%, \mathrm{p}<0.00001\right)$ following acute exercise in the second and third trimester, respectively (see online supplement figure 12). Moreover, there was 'very low' quality evidence (downgraded from 'low' to 'very low' due to serious inconsistency) showing that exercise duration up to $20 \mathrm{~min}$ and between 21 and $40 \mathrm{~min}$ resulted in a mean increase in FHR following acute exercise $(\mathrm{MD}=4.57 \mathrm{bpm}, 95 \% \mathrm{CI} 3.29$ to 5.84 , $\mathrm{I}^{2}=78 \%, \mathrm{p}<0.00001 ; \mathrm{MD}=6.51 \mathrm{bpm}, 95 \% \mathrm{CI} 2.588$ to 10.15 , $\mathrm{I}^{2}=70 \%, \mathrm{p}=0.0004$, respectively), whereas exercising for more than 40 min resulted in no significant change in FHR following acute exercise $\left(\mathrm{MD}=1.38 \mathrm{bpm}, 95 \% \mathrm{CI}-2.28\right.$ to $5.05, \mathrm{I}^{2}=85 \%$, $\mathrm{p}=0.46$; see online supplement figure 13 ). Finally, there was 'very low' quality evidence (downgraded due to serious inconsistency) showing that the measured FHR response following acute maternal exercise varied by method of FHR determination $(p=0.005)$. Specifically, 2D ultrasound measures reported a mean increase in FHR of 8.32 bpm (95\% CI 3.06 to 13.59 , $\left.\mathrm{I}^{2}=84 \%, \mathrm{p}=0.002\right)$, Doppler ultrasound measures reported a mean increase in FHR of $3.46 \mathrm{bpm}$ (95\% CI 2.16 to 4.77, $\left.\mathrm{I}^{2}=86 \%, \mathrm{p}<0.00001\right)$, electronic fetal monitors or telemetry measures reported a mean increase in FHR of $4.66 \mathrm{bpm}$ (95\% CI 2.63 to $\left.6.70, \mathrm{I}^{2}=68 \%, \mathrm{p}<0.00001\right)$ and one study measuring FHR with auscultation reported no change in FHR $\left(\mathrm{MD}=-0.44,95 \% \mathrm{CI}-3.07\right.$ to $2.19, \mathrm{I}^{2}$ not applicable, $\mathrm{p}=0.74$; see online supplement figure 14).

\section{Fetal bradycardia and tachycardia}

There was 'low' quality evidence from eight studies $(n=423$ women, 439 assessments) indicating the proportion of resting bradycardia to be $0 \%\left(95 \%\right.$ CI 0.00 to $0.03, \mathrm{I}^{2}=40 \%$; see online supplement figure 82, Proportions). ${ }^{142444857718687}$ There was 'very low' quality evidence (downgraded due to serious inconsistency) from seven studies ( $\mathrm{n}=755$ women, 859 assessments) showing that fetal bradycardia occurred during $1 \%$ of acute exercise sessions (95\% CI 0.01 to $0.01, \mathrm{I}^{2}=80 \%$; see online supplement figure 84, Proportions) 1404244536888 and 'very low' quality evidence (downgraded due to serious inconsistency) from 22 studies ( $\mathrm{n}=1614$ women, 1825 assessments) reporting fetal bradycardia up to $20 \mathrm{~min}$ following exercise in $1 \%$ of exercise sessions (95\% CI 0.01 to $0.03, \mathrm{I}^{2}=76 \%$; see online supplement figure 86, Proportions). ${ }^{1} 222404244485367687176778688-94$ Artefact was suspected in two studies and they were removed in a post hoc sensitivity analysis (see online supplement figures 83, 85 and 87$).{ }^{193}$ A third study did not specify if they measured the incidence of bradycardia or tachycardia and was not included in the proportion analysis; it stated that there were 'no abnormal FHR tracings'. ${ }^{95}$

There was 'very low' quality evidence (downgraded from 'low' to 'very low' due to serious inconsistency), which reported that the proportion of fetuses experiencing tachycardia increased from $3 \%$ at rest to $5 \%$ during and $7 \%$ following (up to $20 \mathrm{~min}$ ) acute exercise sessions (see online supplement additional results and figures 88-90).

\section{Effect of chronic exercise on fetal heart rate}

There was 'very low' to 'moderate' quality evidence showing no between-group difference or lower resting FHR in women who were active throughout pregnancy (i.e., habitually active) compared with women who were not (see online supplement additional results and figures 15-23). Tests for subgroup analysis were not significant. There was 'very low' to 'low' quality evidence showing no difference in the FHR response during or following acute exercise in women who were active throughout pregnancy compared with women who were not (see online supplement additional results and figures 24-32).

\section{Effect of acute and chronic exercise on umbilical and uterine blood flow metrics}

There was 'low' quality evidence reporting no change in umbilical artery systolic:diastolic ratio from rest to during acute exercise (see online supplement additional results and figure 33). There was no evidence for umbilical artery Resistance Index, Pulsatility Index, volumetric blood flow or mean blood velocity from rest to during exercise. There was 'very low' to 'low' quality evidence showing no change in umbilical artery systolic:diastolic ratio, Pulsatility Index, Resistance Index, volumetric blood flow or mean blood velocity from rest to following acute exercise sessions (see online supplement additional results and figures 33-55). There was no evidence reporting the effects of chronic exercise on resting umbilical artery blood flow metrics or the response of the umbilical artery to acute exercise (see online supplement additional results).

There was 'very low' quality evidence reporting no change in uterine systolic: diastolic ratio from rest to during acute exercise (see online supplement additional results and figure 56). There was no evidence regarding uterine artery Pulsatility Index, Resistance Index, volumetric blood flow or mean blood velocity during exercise. There was 'very low' to 'low' quality evidence showing no change in uterine artery Resistance Index, Pulsatility Index, volumetric blood flow or mean blood velocity from rest to following exercise (see online supplement additional results and figures 57-73). There was 'moderate' quality evidence from one superiority trial, which showed a reduction in resting uterine systolic:diastolic ratio, Pulsatility Index and Resistance Index in yoga compared with walking groups and 'low' quality evidence from one RCT showing no difference in resting uterine Pulsatility Index in women who were active compared with those who were inactive during their pregnancies (see online supplement additional results and figures 74-77). There was no evidence reporting the effects of chronic exercise on resting uterine artery blood flow metrics or the response of the umbilical artery to acute exercise (see online supplement additional results).

\section{DISCUSSION}

This systematic review of 91 studies ( $n=4641$ women) demonstrated an average $6 \mathrm{bpm}$ increase in FHR during acute exercise, which persisted up to 20 min following the exercise cessation. The proportion of fetuses who experienced bradycardia or tachycardia during or following maternal exercise was low. While bradycardia can indicate fetal distress, the events identified during or following exercise were transient $(<2 \mathrm{~min})$ and were not considered clinicaly relevant. Concurrently, metrics of uteroplacental blood flow were either unchanged or slightly altered with acute exercise. Chronic maternal exercise training 
decreased umbilical blood flow (systolic: diastolic ratio, Pulsatility Index and Resistance Index), while uterine blood flow and FHR were unchanged. Together, these data suggest prenatal maternal exercise is not associated with adverse cardiovascular responses of either the fetus or the uteroplacental unit.

\section{Impact of acute exercise on FHR and blood flow in the umbilical and uterine arteries}

There was a small increase in FHR (average of $6 \mathrm{bpm}$ ) was observed during acute maternal exercise, which persisted up to $20 \mathrm{~min}$ following the exercise cessation. In non-pregnant women, acute exercise is associated with an increase in blood flow to the working muscle that is facilitated by decreased perfusion of other vascular beds. ${ }^{84} 96$ This led to the hypothesis that acute prenatal exercise could cause a reduction in uteroplacental blood flow and resultant fetal hypoxia (decrease in oxygen), which would result in increases in FHR. ${ }^{4}$ FHR variability (difference between peak and nadir FHR during 10 min of quiet rest) between 5 and 25 beats is reflective of healthy cardiac responsiveness in the fetus. ${ }^{97}$ Therefore, the observed increase in fetal heart rate with maternal exercise is a normal response.

This systematic review reported that the measures of umbilical and uterine artery blood flow were unchanged with acute maternal exercise. Although studies in rabbits demonstrated acute exercise reduces uterine blood flow, the decrease is attenuated (ie, smaller) in pregnant versus non-pregnant animals. ${ }^{5}$ Indeed, in sheep, fetal oxygenation does not appear to be altered with reductions in blood flow up to $40 \%$ below resting values. ${ }^{98}$ This has not been evaluated in humans, and small decreases in human fetal oxygenation stimulate fetal chemoreceptors and result in the subsequent release of catecholamines by the fetal adrenal medulla to increase FHR. ${ }^{99-101}$ Furthermore, acute exercise stimulates maternal catecholamine release and up to $15 \%$ of released maternal catecholamines can cross the placenta to enter the fetal circulation stimulating changes in fetal arousal (eg, movement), which can increase FHR. ${ }^{6097} 101$ As such, the observed elevation in FHR during and following maternal exercise would be an expected response to maternal acute exercise.

Our meta-analysis revealed a smaller increase in FHR during maternal exercise in the second trimester compared with the third. This may be in part due to the fact that fetal chemoreceptors do not become fully functional until the third trimester. ${ }^{102} 103$ Therefore, any potential decrease in oxygenation or increase in maternal catecholamines would result in less pronounced FHR responses in the second trimester. The clinical relevance of this finding is unclear.

Exercise intensity has been suggested to impact the fetal response to maternal exercise. In the present study, acute bouts of low, moderate and vigorous intensity exercise did not result in significant differences in the FHR response as identified with the post hoc subgroup analysis. However, meta-regressions identified a peak FHR response during acute exercise to be $10 \mathrm{bpm}$ at 138 MET minutes (eg, walking for $40 \mathrm{~min}$ ). The FHR response following acute maternal exercise sessions differed for exercise of varying intensity or duration. Exercise durations greater than 40 min resulted in no significant increase in FHR following acute exercise compared to rest. This may be because many of these exercise sessions were of low intensity (eg, yoga).

Our meta-regressions identified a curvilinear pattern of FHR response following exercise where the peak FHR response following an acute exercise session $(7.2 \mathrm{bpm}$ increase compared with rest) occurred at 174.6 MET minutes (eg, walking for $50 \mathrm{~min})$. Lastly, intensity or duration of acute exercise sessions did not impact the response in umbilical or uterine blood flow metrics. However, of the 91 manuscripts evaluated, only one study included exercise at $>90 \%$ of maximal intensity and demonstrated a $12 \%$ decline in uterine artery systolic:diastolic ratio following exercise. ${ }^{45}$ We do not have data from which to speculate on the response to longer durations of moderate to vigorous intensity exercise or short durations of high intensity exercise ( $>90 \%$ of maximum) at this time.

We also demonstrated that the proportion of fetuses experiencing bradycardia or tachycardia during or following maternal exercise was low (0\%-3\% and 3\%-7\%, respectively). FHR between 80 and $110 \mathrm{bpm}$ does not represent a decrease in fetal deoxygenation in humans. ${ }^{97}$ However, in response to severe hypoxia (ie, fetal acidosis from cardiac block), fetal bradycardia (FHR $<80 \mathrm{bpm}$ ) occurs ${ }^{97} 104$ and 'bradycardia' is one clinical manifestation of fetal distress. ${ }^{105}$ Of the 24 manuscripts evaluated in this meta-analysis, only one study reported four cases of FHR $<80 \mathrm{bpm}$ during exercise; however, technical issues (ie, artefact) were suspected, which would artificially result in a low heart rate reading. ${ }^{1}$ Following maternal exercise, 10 cases across three studies reported FHR $<80 \mathrm{bpm} .{ }^{406777}$ Of the aforementioned studies reporting bradycardia immediately following acute maternal exercise (within $5 \mathrm{~min}$ ), exercise sessions included maternal heart rate near maximal (180 bpm or greater), ${ }^{6777}$ or it was unclear if women had healthy pregnancies (ie, did not have pre-eclampsia or cholestasis). ${ }^{40}$ Furthermore, in each of these cases, FHR returned to normal within 2 min. ${ }^{40} 6777$

Women exercising in the supine position provided $17 \%$ of the cases of reported bradycardia during exercise in the present review. Importantly, transient fetal bradycardia and tachycardia during or following exercise do not necessarily indicate longterm fetal distress, ${ }^{97}$ as the FHR response to stress (eg, maternal exercise) does not correlate with incidence of $\mathrm{C}$-section or birth weight. ${ }^{86}$ Therefore, the observed incidence of transient tachycardia and bradycardia in the present meta-analysis was not considered clinically important.

\section{Impact of chronic exercise on FHR and blood flow metrics in the umbilical and uterine arteries}

Chronic maternal exercise training promotes vascular remodelling and angiogenesis in umbilical and uterine arteries (alongside systemic vasculature). ${ }^{106}$ These adaptations increase vessel diameter and reduce vascular resistance to blood flow. Indeed, umbilical artery systolic:diastolic ratio, Pulsatility Index and Resistance Index decreased in women who exercised while uterine blood flow metrics and FHR were unchanged (see online supplemental figures $15-32,50-55$ and 74-77). This provides evidence that umbilical blood flow resistance is decreased in this population. However, all women, regardless of their exercise status (ie, exercise and control groups; including one study with women who had gestational diabetes mellitus), ${ }^{107}$ had umbilical artery blood flow metrics within the normal range of expected values (50-90th percentile) for their gestational age. ${ }^{108}$ Although beyond the scope of that review (athletes were excluded), maternal training status may impact the physiological ability to redirect blood flow from the uteroplacental unit to the working muscles of the mother.

\section{Strengths and limitations}

Our comprehensive systematic review included all study types (except case studies) and data from 19 countries (six continents). We assimilated and evaluated the evidence using rigorous methodological standards (eg, GRADE). To our knowledge, this is 
the first meta-analysis on FHR and umbilical and uterine artery blood flow responses to acute prenatal exercise.

One limitation of this analysis is that the relative incidence of bradycardia or tachycardia reported by this review is likely overestimated due to inconsistencies in the range of definitions used, and that many studies that collected FHR measurements did not report on bradycardia or tachycardia. Indeed, a large cohort study by Pildner von Steinburg et al ${ }^{109}$ showed the incidence of bradycardia and tachycardia at rest (exercise was not examined) to be $0.12 \%$ and $3.71 \%$, respectively, whereas we reported a $95 \% \mathrm{CI}$ of $0 \%$ to $3 \%$ for bradycardia and $0 \%$ to $14 \%$ for tachycardia. Future studies looking at FHR longitudinally (ie, comparing incidence of bradycardia and tachycardia at rest, during and following exercise) are required. This methodology will allow us to differentiate between women whose fetuses develop bradycardia (or tachycardia) during exercise but resolve in the recovery period, who develop abnormal FHR following exercise only or who have fetuses that show signs of distress before exercise has begun (eg, bradycardia in the supine body position). In the future, publications that report on FHR should include the incidence and duration of bradycardia and tachycardia so that the reader will be able to make better judgements about the safety of prenatal exercise with respect to acute fetal distress. The highest exercise intensity included in this review was $92 \%$ of predicted maximal heart rate. There is currently no evidence available for higher intensities.

One last limitation of this study is the dearth of data regarding chronic exercise (eg, exercise intervention) and resting values and responses for FHR, umbilical and uterine blood flow metrics. In the present review, the evidence for umbilical artery blood flow responses during and following chronic maternal exercise was graded as 'very low' to 'moderate', and there were only one or two manuscripts included in the pooled analysis for each (three total for all measures). ${ }^{37107110}$ High-quality studies are required to identify whether chronic exercise negatively impacts umbilical blood flow metrics at rest.

\section{CONCLUSION}

Prenatal exercise was not associated with clinically relevant FHR or uteroplacental responses to acute or chronic exercise. Together, these data suggest prenatal exercise is not associated with adverse cardiovascular responses of either the fetus or within the umbilical and uterine vasculature. However, there remains a gap in knowledge with regard to these variable in the setting of longer duration exercise and near-maximal exercise intensity.

\section{Author affiliations}

${ }^{1}$ Program for Pregnancy and Postpartum Health, Physical Activity and Diabetes Laboratory, Faculty of Kinesiology, Sport, and Recreation, Women and Children's Health Research Institute, Alberta Diabetes Institute, University of Alberta, Edmonton, Alberta, Canada

${ }^{2}$ R. Samuel McLaughlin Foundation-Exercise and Pregnancy Laboratory, School of Kinesiology, Faculty of Health Sciences, Department of Anatomy and Cell Biology, Schulich School of Medicine and Dentistry, Children's Health Research Institute, The University of Western Ontario, London, Ontario, Canada

${ }^{3}$ Department of Obstetrics and Gynecology, Queen's University, Kingston, Ontario, Canada

${ }^{4}$ Independent researcher, Ottawa, Ontario, Canada

${ }^{5}$ Healthy Active Living and Obesity Research Group, Children's Hospital of Eastern Ontario Research Institute, Ottawa, Ontario, Canada

${ }^{6}$ Clinical Research Unit, Children's Hospital of Eastern Ontario Research Institute, Ottawa, Ontario, Canada

${ }^{7} J o h n$ W. Scott Health Sciences Library, University of Alberta, Edmonton, Alberta, Canada

${ }^{8}$ School of Human Kinetics, Faculty of Health Sciences, University of Ottawa, Ottawa, Ontario, Canada
${ }^{9}$ Facultad de Ciencias de la Actividad Física y del Deporte—INEF, Universidad Politécnica de Madrid, Madrid, Spain

${ }^{10}$ Department of Human Kinetics, Université du Québec à Trois-Rivières, Trois-Rivieres, Quebec, Canada

Acknowledgements The authors wish to acknowledge Mary Duggan from the Canadian Society for Exercise Physiology who is the primary knowledge user for the Canadian Institute of Health Research Knowledge Synthesis Grant.

Contributors MHD, S-MR, MFM, GAD and KBA contributed to the conception of the study. MHD, S-MR, MFM, GAD, KBA, AJG, NB, VJP, CEG, LGS and RB contributed to the design of the study and development of the search strategy. LGS conducted the systematic search. RS and VLM completed the acquisition of data. RS, MHD and NB performed the data analysis. All authors assisted with the interpretation. RS and MHD were the principal writers of the manuscript. All authors contributed to the drafting and revision of the final article. All authors approved the final submitted version of the manuscript.

Funding Canadian Institute of Health Research Knowledge Synthesis Grant (grant number 140995). MHD is funded by an Advancing Women's Heart Health Initiative New Investigator Award supported by Health Canada and the Heart and Stroke Foundation of Canada (grant number RES0033140). RS is funded by a Canadian Institutes for Health Research Doctoral Research Award (grant number GSD146252).

Competing interests None declared.

Patient consent Not required.

Provenance and peer review Not commissioned; externally peer reviewed.

\section{REFERENCES}

1 Jovanovic L, Kessler A, Peterson CM. Human maternal and fetal response to graded exercise. J App/ Physiol 1985;58:1719-22.

2 Rafla NM, Cook JR. The effect of maternal exercise on fetal heart rate. J Obstet Gynaecol 1999;19:381-4.

3 Macones GA, Hankins GD, Spong CY, et al. The 2008 National Institute of Child Health and Human Development workshop report on electronic fetal monitoring: update on definitions, interpretation, and research guidelines. J Obstet Gynecol Neonatal Nurs 2008;37:510-5.

4 CLAPP JF, Rokey R, Treadway JL, et al. Exercise in pregnancy. Medicine \& Science in Sports \& Exercise 1992;24:294???300.

5 O'Hagan KP, Alberts JA. Uterine artery blood flow and renal sympathetic nerve activity during exercise in rabbit pregnancy. Am J Physiol Regul Integr Comp Physiol 2003;285:R1135-44.

6 Zimmermann P, Eiriö V, Koskinen J, et al. Doppler assessment of the uterine and uteroplacental circulation in the second trimester in pregnancies at high risk for pre-eclampsia and/or intrauterine growth retardation: comparison and correlation between different Doppler parameters. Ultrasound Obstet Gynecol 1997;9:330-8.

7 Monga M. Fetal heart rate response to maternal exercise. Clin Obstet Gynecol 2016;59:568-75.

8 Wiebe HW, Boulé NG, Chari R, et al. The effect of supervised prenatal exercise on fetal growth: a meta-analysis. Obstet Gynecol 2015;125:1185-94.

9 Davies GA, Wolfe LA, Mottola MF, et al. Joint SOGC/CSEP clinical practice guideline: exercise in pregnancy and the postpartum period. Can J App/ Physiol 2003;28:330-41.

10 Anon. ACOG committee opinion no. 650: physical activity and exercise during pregnancy and the postpartum period. Obstet Gyneco 2015;126:135.

11 Evenson KR, Barakat R, Brown WJ, et al. Guidelines for physical activity during pregnancy: comparisons from around the world. Am J Lifestyle Med 2014;8:102-21.

12 Mottola MF, Davenport MH, Ruchat S-M, et al. 2019 Canadian guideline for physical activity throughout pregnancy. Br J Sports Med 2018;52:1339-46.

13 Liberati A, Altman DG, Tetzlaff J, et al. The PRISMA statement for reporting systematic reviews and meta-analyses of studies that evaluate healthcare interventions: explanation and elaboration. BMJ 2009;339:b2700.

14 Moher D, Shamseer L, Clarke M, et al. Preferred reporting items for systematic review and meta-analysis protocols (PRISMA-P) 2015 statement. Syst Rev 2015;4:1.

15 Artal R. Exercise in pregnancy: guidelines. Clin Obstet Gynecol 2016;59:639-44.

16 Caspersen CJ, Powell KE, Christenson GM. Physical activity, exercise, and physical fitness: definitions and distinctions for health-related research. Public Health Rep 1985; 100:126-31.

17 Balshem H, Helfand M, Schünemann HJ, et al. GRADE guidelines: 3. Rating the quality of evidence. J Clin Epidemiol 2011;64:401-6.

18 Higgins JPT. Cochrane handbook for systematic reviews of interventions. S.l.: Cochrane Collaboration, 2011.

19 Guyatt GH, Oxman AD, Vist G, et al. GRADE guidelines: 4. Rating the quality of evidence —study limitations (risk of bias). J Clin Epidemiol 2011;64:407-15.

20 Chen S, Song X, Chen Z, et al. CD133 expression and the prognosis of colorectal cancer: a systematic review and meta-analysis. PLoS One 2013;8:e56380. 
21 Norton K, Norton L, Sadgrove D. Position statement on physical activity and exercise intensity terminology. J Sci Med Sport 2010;13:496-502.

22 Brenner IK, Wolfe LA, Monga M, et al. Physical conditioning effects on fetal heart rate responses to graded maternal exercise. Med Sci Sports Exerc 1999;31:792-9.

23 McMurray RG, Katz VL, Poe MP, et al. Maternal and fetal responses to low-impact aerobic dance. Am J Perinatol 1995;12:282-5.

24 Lynch AM, McDonald S, Magann EF, et al. Effectiveness and safety of a structured swimming program in previously sedentary women during pregnancy. J Matern Fetal Neonatal Med 2003;14:163-9.

25 Collings CA, Curet LB, Mullin JP. Maternal and fetal responses to a maternal aerobic exercise program. Am J Obstet Gynecol 1983;145:702-7.

26 Katz VL, McMurray R, Berry MJ, et al. Fetal and uterine responses to immersion and exercise. Obstet Gynecol 1988;72:225-30.

27 Sibley L, Ruhling RO, Cameron-Foster J, et al. Swimming and physical fitness during pregnancy. J Nurse Midwifery 1981;26:3-12.

28 Katz VL, McMurray R, Goodwin WE, et al. Nonweightbearing exercise during pregnancy on land and during immersion: a comparative study. Am J Perinatol 1990;7:281-4.

29 Ruissen $C$, Jager $W$, von Drongelen $M$, et al. The influence of maternal exercise on the pulsatility index of the umbilical artery blood velocity waveform. Eur J Obstet Gynecol Reprod Biol 1990;37:1-6.

30 van Doorn MB, Lotgering FK, Struijk PC, et al. Maternal and fetal cardiovascular responses to strenuous bicycle exercise. Am J Obstet Gynecol 1992;166:854-9.

31 Watson WJ, Katz VL, Hackney AC, et al. Fetal responses to maximal swimming and cycling exercise during pregnancy. Obstet Gynecol 1991;77:382-6.

32 Clapp JF, Stepanchak W, Tomaselli J, et al. Portal vein blood flow-effects of pregnancy, gravity, and exercise. Am J Obstet Gynecol 2000;183:167-72.

33 Baciuk EP, Pereira RI, Cecatti JG, et al. Water aerobics in pregnancy: cardiovascular response, labor and neonatal outcomes. Reprod Health 2008:5:10.

34 Chaddha V, Simchen MJ, Hornberger LK, et al. Fetal response to maternal exercise in pregnancies with uteroplacental insufficiency. Am J Obstet Gynecol 2005;193:995-9.

35 Silveira C, Pereira BG, Cecatti JG, et al. Fetal cardiotocography before and after water aerobics during pregnancy. Reprod Health 2010;7:23.

36 Bgeginski R, Almada BP, Kruel LF. Fetal heart rate responses during maternal resistance exercise: a pilot study. Rev Bras Ginecol Obstet 2015:37:133-9.

37 Rakhshani A, Nagarathna R, Mhaskar R, et al. Effects of yoga on utero-fetalplacental circulation in high-risk pregnancy: a randomized controlled trial. Adv Prev Med 2015;2015:1-10.

38 Clapp JF. Fetal heart rate response to running in midpregnancy and late pregnancy. Am J Obstet Gynecol 1985;153:251-2.

39 Cooper KA, Hunyor SN, Boyce ES, et al. Fetal heart rate and maternal cardiovascular and catecholamine responses to dynamic exercise. Aust N Z J Obstet Gynaecol 1987;27:220-3.

40 Rauramo I. Effect of short-term physical exercise on foetal heart rate and uterine activity in normal and abnormal pregnancies. Ann Chir Gynaecol 1987;76:274-9.

41 Sørensen KE, Børlum KG. Fetal heart function in response to short-term maternal exercise. Br J Obstet Gynaecol 1986;93:310-3.

42 Paolone AM, Shangold M, Paul D, et al. Fetal heart rate measurement during maternal exercise-avoidance of artifact. Med Sci Sports Exerc 1987;19:605???609-9.

43 Arfi JS, Peres G. Frequences cardiaques maternelle et foetale lors d'exercises sur ergocycle. J Gynecol Obstet Biol Reprod 1986;15:281-6.

44 Avery ND, Stocking KD, Tranmer JE, et al. Fetal responses to maternal strength conditioning exercises in late gestation. Can J Appl Physiol 1999;24:362-76.

45 Erkkola RU, Pirhonen JP, Kivijärvi AK. Flow velocity waveforms in uterine and umbilical arteries during submaximal bicycle exercise in normal pregnancy. Obstet Gynecol 1992;79:611-5.

46 Clapp JF, Little KD, Capeless EL. Fetal heart rate response to sustained recreationa exercise. Am J Obstet Gynecol 1993;168:198-206.

47 Jeffreys RM, Stepanchak W, Lopez B, et al. Uterine blood flow during supine rest and exercise after 28 weeks of gestation. BJOG 2006;113:1239-47.

48 Babbar S, Hill JB, Williams KB, et al. Acute feTal behavioral Response to prenatal Yoga: a single, blinded, randomized controlled trial (TRY yoga). Am J Obstet Gynecol 2016;214:399

49 Perales Santaella M, Mateos S, Vargas M, et al. Fetal and maternal heart rate responses to exercise in pregnant women. A randomized Controlled Trial. Arch Med Deporte 2015;32:361-7.

50 Roldan 0 , Perales M, Mateos $\mathrm{S}$, et al. Supervised physical activity during pregnancy improves fetal cardiac response. Revista Internacional De Medicina Y Ciencias De La Actividad Fisica Y Del Deporte 2015;15:757-72.

51 Bung $P$, Bung C, Artal R, et al. Therapeutic exercise for insulin-requiring gestational diabetics: effects on the fetus - results of a randomized prospective longitudinal study. J Perinat Med 1993;21:125-37.

52 Nabeshima Y, Sasaki J, Mesaki N, et al. Effect of maternal exercise on fetal umbilical artery waveforms: the comparison of IUGR and AFD fetuses. J Obstet Gynaecol Res 1997;23:255-9.
53 Dale E, Mullinax KM, Bryan DH. Exercise during pregnancy: effects on the fetus. Can J App/ Sport Sci 1982;7:98-103.

54 Polis RL, Gussman D, Kuo YH. Yoga in pregnancy: an examination of maternal and fetal responses to 26 yoga postures. Obstet Gynecol 2015;126:1237-41.

55 O'Neill ME, Cooper KA, Boyce ES, et al. Postural effects when cycling in late pregnancy. Women Birth 2006;19:107-11.

56 Barakat-Carballo R, Stirling J, Zakynthinaki M, et al. Acute maternal exercise during the third trimester of pregnancy, influence on foetal heart rate. (Ejercicio físico durante el tercer trimestre de embarazo, influencia en la frecuencia cardiaca fetal). RICYDE. Revista Internacional de Ciencias del Deporte 2008:4:33-43.

57 Vega SR, Kleinert J, Sulprizio M, et al. Responses of serum neurotrophic factors to exercise in pregnant and postpartum women. Psychoneuroendocrinology 2011:36:220-7.

58 May LE, Suminski RR, Berry A, et al. Maternal physical activity mode and fetal heart outcome. Early Hum Dev 2014;90:365-9.

59 Morrow RJ, Ritchie JW, Bull SB. Fetal and maternal hemodynamic responses to exercise in pregnancy assessed by Doppler ultrasonography. Am J Obstet Gynecol 1989;160:138-40.

60 Artal R, Rutherford $S$, Romem $Y$, et al. Fetal heart rate responses to maternal exercise. Am J Obstet Gynecol 1986;155:729-33.

61 Steegers EA, Buunk G, Binkhorst RA, et al. The influence of maternal exercise on the uteroplacental vascular bed resistance and the fetal heart rate during normal pregnancy. Eur J Obstet Gynecol Reprod Biol 1988;27:21-6.

62 Collings C, Curet LB. Fetal heart rate response to maternal exercise. Am J Obstet Gynecol 1985; 151:498-501.

63 Veille JC, Hohimer AR, Burry K, et al. The effect of exercise on uterine activity in the last eight weeks of pregnancy. Am J Obstet Gynecol 1985;151:727-30.

64 Pomerance JJ, Gluck L, Lynch VA. Maternal exercise as a screening test for uteroplacental insufficiency. Obstet Gynecol 1974;44:383-7.

65 Marsál K, Löfgren 0, Gennser G. Fetal breathing movements and maternal exercise. Acta Obstet Gynecol Scand 1979;58:197-201.

66 Lotgering FK, Spinnewijn WE, Struijk PC, et al. Respiratory and metabolic responses to endurance cycle exercise in pregnant and postpartum women. Int I Sports Med 1998; 19:193-8

67 Manders MA, Sonder GJ, Mulder EJ, et al. The effects of maternal exercise on fetal heart rate and movement patterns. Early Hum Dev 1997;48:237-47.

68 Webb KA, Wolfe LA, McGrath MJ. Effects of acute and chronic maternal exercise on fetal heart rate. J App/ Physiol 1994;77:2207-13.

69 Pijpers L, Wladimiroff JW, McGhie J. Effect of short-term maternal exercise on maternal and fetal cardiovascular dynamics. Br J Obstet Gynaecol 1984;91:1081-6.

70 Szymanski LM, Satin AJ. Strenuous exercise during pregnancy: is there a limit? Am J Obstet Gynecol 2012;207:179.e1-179.e6.

71 MacPhail A, Davies GA, Victory R, et al. Maximal exercise testing in late gestation: fetal responses. Obstet Gynecol 2000;96:565-70.

72 Bonnin P, Bazzi-Grossin C, Ciraru-Vigneron N, et al. Evidence of fetal cerebral vasodilatation induced by submaximal maternal dynamic exercise in human pregnancy. J Perinat Med 1997;25:63-70.

73 Kennelly MM, Geary M, McCaffrey N, et al. Exercise-related changes in umbilical and uterine artery waveforms as assessed by Doppler ultrasound scans. Am J Obstet Gynecol 2002;187:661-6.

74 O'Neill ME. Maternal rectal temperature and fetal heart rate responses to upright cycling in late pregnancy. Br J Sports Med 1996;30:32-5.

75 Tuffnell DJ, Buchan PC, Albert D, et al. Fetal heart rate responses to maternal exercise, increased maternal temperature and maternal circadian variation. J Obstet Gynaecol 1990;10:387-91.

76 Bonen A, Campagna PD, Gilchrist L, et al. Substrate and hormonal responses during exercise classes at selected stages of pregnancy. Can J App/ Physiol 1995;20:440-51

77 Carpenter MW, Sady SP, Hoegsberg B, et al. Fetal heart rate response to maternal exertion. JAMA 1988;259:3006-9.

78 Dressendorfer RH, Goodlin RC. Fetal heart rate response to maternal exercise testing. Phys Sportsmed 1980;8:90-4

79 Nesler CL, Hassett SL, Cary S, et al. Effects of supine exercise on fetal heart rate in the second and third trimesters. Am J Perinatol 1988:5:159-63.

80 Smoler ED, Armass Dominguez J, Dominguez M, et al. Maternal exercise and cardiac rate in the mother and the fetus. I. A comparative electrocardiographic study using two different simple exercise tolerance tests. [Spanish]. Archivos de Investigacion Medica 1974:5:595-602.

81 Jones RL, Botti JJ, Anderson WM, et al. Thermoregulation during aerobic exercise in pregnancy. Obstet Gynecol 1985:65:340-5.

82 Hauth JC, Gilstrap LC, Widmer K. Fetal heart rate reactivity before and after maternal jogging during the third trimester. Am J Obstet Gynecol 1982;142:545-7.

83 Clapp JF, Little KD, Appleby-Wineberg SK, et al. The effect of regular maternal exercise on erythropoietin in cord blood and amniotic fluid. Am J Obstet Gynecol 1995:172:1445-51.

84 Baumann H, Huch A, Huch R. Doppler sonographic evaluation of exercise-induced blood flow velocity and waveform changes in fetal, uteroplacental and large maternal vessels in pregnant women. J Perinat Med 1989;17:279-87. 
85 Golomer E, Arfi JS, Sud R, et al. [Exercise and pregnancy. Study of the change in heart rate in pregnancy when performing standardized moderate exercise]. J Gynecol Obstet Biol Reprod 1989;18:295-302.

86 Kennelly MM, McCaffrey N, McLoughlin P, et al. Fetal heart rate response to strenuous maternal exercise: not a predictor of fetal distress. Am J Obstet Gynecol 2002;187:811-6.

87 Avery MD, Leon AS, Kopher RA. Effects of a partially home-based exercise program for women with gestational diabetes. Obstet Gynecol 1997;89:10-15.

88 Hall DC, Kaufmann DA. Effects of aerobic and strength conditioning on pregnancy outcomes. Am J Obstet Gynecol 1987;157:1199-203.

89 Artal R, Fortunato V, Welton A, et al. A comparison of cardiopulmonary adaptations to exercise in pregnancy at sea level and altitude. Am J Obstet Gynecol 1995; 172:1170-80.

90 Artal R, Catanzaro RB, Gavard JA, et al. A lifestyle intervention of weight-gain restriction: diet and exercise in obese women with gestational diabetes mellitus. Appl Physiol Nutr Metab 2007;32:596-601.

91 Rafla NM, Beazely JM. The effect of maternal exercise on fetal umbilical artery waveforms. Eur J Obstet Gynecol Reprod Biol 1991;40:119-22.

92 Kardel KR, Johansen B, Voldner N, et al. Association between aerobic fitness in late pregnancy and duration of labor in nulliparous women. Acta Obstet Gynecol Scand 2009;88:948-52.

93 Artal R, Romem Y, Paul RH, et al. Fetal bradycardia induced by maternal exercise. Lancet 1984;2:258-60.

94 Veille JC, Bacevice AE, Wilson B, et al. Umbilical artery waveform during bicycle exercise in normal pregnancy. Obstet Gynecol 1989;73:957-60.

95 Lindqvist PG, Marsal K, Merlo J, et al. Thermal response to submaximal exercise before, during and after pregnancy: a longitudinal study. J Matern Fetal Neonatal Med 2003;13:152-6.

96 Rowell LB, O'Leary DS. Reflex control of the circulation during exercise: chemoreflexes and mechanoreflexes. J App/ Physiol 1990;69:407-18.

97 Freeman RK, Garite TJ, Nageotte MP. Fetal heart rate monitoring. 3 edn. Philadelphia: Lippincott Williams \& Wilkins, 2003
98 Lotgering FK, Gilbert RD, Longo LD. Exercise responses in pregnant sheep: blood gases, temperatures, and fetal cardiovascular system. J Appl Physiol Respir Environ Exerc Physiol 1983;55:842-50.

99 Cohen WR, Piasecki GJ, Cohn HE, et al. Adrenal secretion of catecholamines during hypoxemia in fetal lambs. Endocrinology 1984;114:383-90.

100 Parer JT, Livingston EG. What is fetal distress? Am J Obstet Gynecol 1990;162:1421-7.

101 Wolfe LA, Brenner IK, Mottola MF, et al. Maternal exercise, fetal well-being and pregnancy outcome. Exerc Sport Sci Rev 1994;22:145.

102 Dawes GS, Duncan SL, Lewis BV, et al. Hypoxaemia and aortic chemoreceptor function in foetal lambs. J Physiol 1969;201:105-16.

103 Walker AM, Cannata JP, Dowling MH, et al. Age-dependent pattern of autonomic heart rate control during hypoxia in fetal and newborn lambs. Biol Neonate 1979;35:198-208.

104 Acker H. Chemoreceptor and baroreceptor function with respect to fetal heart rate variability. New York: Springer-Verlag, 1985:223-33.

105 Maeda K. Modalities of fetal evaluation to detect fetal compromise prior to the development of significant neurological damage. J Obstet Gynaecol Res 2014;40:2089-94.

106 Skow RJ, King EC, Steinback CD, et al. The influence of prenatal exercise and preeclampsia on maternal vascular function. Clin Sci 2017;131:2223-40.

107 E-Mekawy HS, Sabbour AA, Radwan MM. Effect of antenatal exercises on umbilical blood flow and neonate wellbeing in diabetic pregnant women. Indian J Physiother Occup Ther 2016:6:121-5.

108 Acharya G, Wilsgaard T, Berntsen GK, et al. Reference ranges for serial measurements of umbilical artery Doppler indices in the second half of pregnancy. Am J Obstet Gynecol 2005;192:937-44.

109 Pildner von Steinburg S, Boulesteix AL, Lederer C, et al. What is the "normal" fetal heart rate? PeerJ 2013;1:e82.

110 Okido MM, Valeri FL, Martins WP, et al. Assessment of foetal wellbeing in pregnant women subjected to pelvic floor muscle training: a controlled randomised study. Int Urogynecol J 2015;26:1475-81. 